\title{
PERENCANAAN KAPASITAS PRODUKSI DENGAN METODE CAPACITY REQUIREMENT PLANNING DI TEACHING FACTORY MANUFACTURE ELECTRONICS POLITEKNIK NEGERI BATAM
}

\author{
Rika Kartika Sihotang ${ }^{1}$ ) Aditya Wirangga,ST.,M.AB ${ }^{2}$ ) \\ 1) Prodi Administrasi Bisnis Terapan Politeknik Negeri Batam, email: rikakartika.sihotang@ gmail.com \\ 2) Prodi Administrasi Bisnis Terapan Politeknik Negeri Batam, email: aditya @ polibatam.ac.id
}

\begin{abstract}
Abstrak
Penelitian ini bertujuan untuk menerapkan kapasitas waktu produksi yang sesuai dengan menggunakan metode Capacity Requirement Planning pada Teaching Factory Manufacture Electronics (TFME) Politeknik Negeri Batam. Variable dalam penelitain ini adalah jadwal pesanan (Schedule Of Planned Order Release), pusat kerja (Work Centre), Routing Data (waktu yang digunakan), dan Work Order Status. Pengumpulan data diperoleh dari data dokumen produksi di TFME Politeknik Negeri Batam. Hasil penelitian dapat disimpulkan bahwa pesanan dapat diselesaikan dengan kapasitas perhari yaitu 8 pcs/hari setara 1 unit PCB A4 dengan waktu operasi adalah waktu yang digunakan untuk menyelesaikan permintaan berdasarkan kemampuan kapasitas maximal. Sehingga perumusannya adalah permintaan (demand) dibagi dengan kapasitas produksi terpasang yaitu $165 \mathrm{pcs}: 8 \mathrm{pcs} / \mathrm{hari}=$ 21 unit dimana 1 unit PCB A4dikerjakan dalam waktu 5,12 jam sehingga untuk menyelesaikan 21 unit menghabiskan waktu selama 107,52 jam $=14$ hari, untuk itu berdasarkan kebutuhan penyesuaian kapasitas dalam produksi maka jumlah hari yang dibutuhkan untuk Operation Time (waktu operasi) adalah selama 14 hari. Kebutuhan waktu aktual adalah konversi dari waktu operasi kedalam satuan menit yaitu 5,12 jam/unit x 21 unit x 60 menit $=6451$ menit $=107,52$ jam.tingkat efisiensi dan utilisasi merupakan kondisi actual perfomance dari setiap work centres. Kapasitas yang tersedia dalam periode ini selama 4032 menit untuk menyelesaikan pesanan PCB GRobo sebanyak 165 pcs, dan waktu aktual yang dibutuhkan untuk menyelesaikan pesanan tersebut hanya 6451 menit sehingga dengan menggunakan metode CRP ini dapat menyimpan operation cost selama 2419 menit $=40,32$ jam $=6$ hari kerja sehingga TFME Politeknik Negeri Batam dapat meminimalisir biaya yang diakibatkan dari proses produksi serta pesanan untuk PCB G-Robo juga dapat diselesaikan tepat pada waktunya.
\end{abstract}

Kata kunci : Capacity Requirement Planning, Kapasitas Produksi, Work Centre 


\section{PENDAHULUAN}

Ketatnya persaingan industri dalam bidang manufaktur di Indonesia yang menuntut setiap perusahaan manufaktur memiliki keunggulan dari para pesaing yang sejenis. Salah satu keunggulan yang harus dimiliki perusahaan yaitu, dapat memenuhi permintaan pasar dengan cepat dan sesuai dengan waktu yang ditentukan, serta menghasilkan produk yang berkualitas dan bernilai jual. Secara periode bulanan dalam rentang waktu Januari 2014 sampai September 2015 seperti laporan yang dibuat oleh Badan Pusat Statistik yaitu Indeks Produksi Total Industri Manufaktur Besar dan Sedang selalu berada diatas level dan menjadi the leading sector terhadap PDB mencapai 20,41\% sejak tahun 2010.

Teaching Factory Manufacture Electonics (TFME) Politeknik Negeri Batam merupakan unit layanan pendukung yang menerapkan penggabungan konsep antara pembelajaran berupa laboratorium pendidikan dan penerimaan pesanan dengan industri manufaktur. TFME memiliki fungsi sebagai unit layanan yang bergerak dibidang jasa dan produksi, karena dapat menghasilkan komponen elektronik. TFME Politeknik Negeri Batam harus dapat memproduksi dengan baik dan meningkatkan kualitas produk serta mampu bersaing dari segi pelayanan, karena konsumen suatu produk tidak menginginkan produk yang mereka pesan tidak sampai sesuai dengan jadwal pesanan yang diinginkan. Untuk itu perencanaan kapasitas memberikan kontribusi bagi perusahaan untuk menentukan tingkat kapasitas yang dibutuhkan dalam melakukan penjadwalan produksi yang bermanfaat bagi pencapaian target produksi, jika terjadi kekurangan waktu produksi hasilnya akan mengalami kekurangan target produksi maka pengiriman ke konsumen juga akan terlambat dan sebaliknya jika mengalami kelebihan kapasitas produksi akan berdampak pada utilisasi sumber daya rendah, operasi produksi tidak efisien, peningkatan biaya produksi dan berkurangnya margin keuntungan perusahaan. Hal inilah yang akan menjadi dasar pertimbangan bagi penulis untuk melakukan peneliatain yang berjudul "Perencanaan Kapasitas Produksi Dengan Metode Capacity Requirement Planning di Teaching Factory Manufacture Electronics Politeknik Negeri Batam".

\section{PERUMUSAN MASALAH}

Maka dapat dirumuskan permasalahan terkait kapasitas produksi di TFME adalah bagaimana merencanakan kapasitas produksi dengan menggunakan metode Capacity Requirement Planning sehingga dapat menyesuaikan antara jumlah permintaan dengan kapasitas yang tersedia di TFME Politeknik Negeri Batam.

\section{TUJUAN PENELITIAN}

Tujuan penelitian ini dilakukan untuk dapat merencanakan kapasitas produksi dengan menggunakan metode Capacity Requirement Planning di TFME Politeknik Negeri Batam.

\section{BATASAN MASALAH}

Pembatasan masalah dimaksudkan agar penelitian dapat terarah dan sederhana sesuai dengan tujuan dari penelitian. Batasan masalah dalam penelitian ini mengenai perencanaan kapasitas produksi untuk produksi PCB (Printed Circuit Board) Double Layer sebagai basic atau landasan dasar untuk penempatan komponen dalam membuat produk G-Robo di TFME Politeknik Negeri Batam. Kegiatan produksi diasumsikan berlangsung normal tanpa ada mesin atau peralatan yang macet atau rusak total, listrik padam, kecelakaan kerja, kekurangan material dan lainnya.

\section{MANFAAT PENELITIAN}

Praktis, bagi perusahaan memberikan masukan berupa bahan untuk evaluasi dalam kegiatan perencanaan produksi, sehingga perusahaan dapat mengetahui kemampuan produksi dalam periode waktu tersebut. Manfaat Teoritis, bagi pembaca dan penulis Bagi pembaca dapat dijadikan sebagai sumber pengetahuan dan referensi bagi pihak - pihak 
Rika Kartika S \& Aditya Wirangga, Perencanaan Kapasiatas Produksi Dengan...

yang ingin mempelajari ataupun yang akan melakukan penelitian yang terkait dengan penelitian penulis guna untuk penelitian yang lebih lanjut atau yang lebih berkembang lagi. Bagi penulis sebagai pembelajaran mengenai proses produksi yang akan diteliti

\section{KAJIAN PUSTAKA}

Literatur (Kajian Empiris)

Adapun landasan jurnal dan teori yang digunakan oleh penulis sebagai acuan dasar

\begin{tabular}{|c|c|c|c|c|}
\hline No & Peneliti & Judul & Variabel & Hasil Penelitian \\
\hline 1 & $\begin{array}{l}\text { Ikedanaka- } \\
\text { machi, dkk } \\
\text { (Int. Scientific } \\
\text { Romac : } \\
\text { 2014) }\end{array}$ & \begin{tabular}{lr}
\multicolumn{2}{l}{ Stability-Based Short Time } \\
Capacity & Requirement \\
Planning & Under \\
Uncertainty &
\end{tabular} & $\begin{array}{lr}\text { CRP, } & \text { Schedule } \\
\text { Stability, } & \text { Resource } \\
\text { Project } & \text { Scheduling } \\
\text { Mathematical Model }\end{array}$ & $\begin{array}{l}\text { Mengacu pada Stabilitas dari rencana kebutuhan CRP dirilis } \\
\text { dengan kebutuhan kapasitas dan beban serta menandakan } \\
\text { kekokohan proses manufaktur terhadap ketidak pastian } \\
\text { sumber daya. Dengan metode CRP dapat diterapkan pada } \\
\text { sistem manufaktur yang fleksibel seperti job shop }\end{array}$ \\
\hline 2 & $\begin{array}{l}\text { Erlina P } \\
\text { (ISSN:1907- } \\
5146 ., \\
\text { 2009Vol. } 4, \\
\text { No. } 1\end{array}$ & 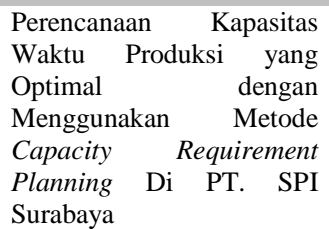 & $\begin{array}{l}\text { Perencanaan } \\
\text { Kebutuhan } \\
\text { Kapasitas, CRP }\end{array}$ & $\begin{array}{l}\text { Pada bulan Juli sampai dengan bulan Juni } 2008 \text { kapasitas } \\
\text { yang tersedia sebesar } 266.872 \text { menit per tahun, sedangkan } \\
\text { kebutuhan aktualnya } 269.681 \text { menit per tahun, dan kapasitas } \\
\text { mesin mempunyai kekurangan kapasitas pertahunnya yaitu } \\
\text { sebesar } 28.087 \text { menit. }\end{array}$ \\
\hline 3 & $\begin{array}{l}\text { Centya } \\
\text { Anasthesia } \\
\text { Nainggolan } \\
(2015)\end{array}$ & $\begin{array}{l}\text { Perencanaan Kapasitas } \\
\text { Produksi dengan Capacity } \\
\text { Requirement Planning Di } \\
\text { PT. Sinar Utama Nusantara }\end{array}$ & Kapasitas, & $\begin{array}{l}\text { Menghasilkan perbandingan jumlah kebutuhan kapasitas } \\
\text { dengan kapasitas yang tersedia selama } 3 \text { periode didapatkan } \\
\text { hasil setiap periodenya terjadi kekurangan kapasitas pada } \\
\text { pencetakan bulan Januari - Maret } 2015 \text { dan Socketing bulan } \\
\text { Januari 2015. Dilakukan perbaikan dengan melakukan } \\
\text { penambahan jumlah jam kerja didapatkan hasil seluruh } \\
\text { kapasitas work centre terpenuhi. }\end{array}$ \\
\hline 4 & $\begin{array}{l}\text { Yovial } \\
\text { Achbar (2010) }\end{array}$ & 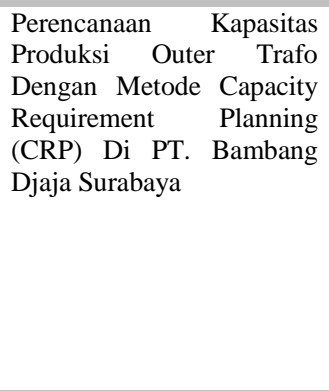 & $\begin{array}{l}\text { Perencanaan } \\
\text { Kebutuhan } \\
\text { Kapasitas, CRP }\end{array}$ & $\begin{array}{l}\text { Pada perhitungan kekurangan kapasitas waktu produksi bulan } \\
\text { Januari-Desember } 2009 \text { dapat diketahui bahwa dengan } \\
\text { metode perusahaan mengalami total kekurangan kapasitas } \\
\text { waktu sebesar }-433,65 \text { jam, sedangkan menggunakan metode } \\
\text { CRP mengalami kekurangan waktu sebesar }-282,1 \text { jam, } \\
\text { sehingga metode CRP lebih baik, dalam memenuhi } \\
\text { permintaan pada bulan Juli } 2010-\text { Juni } 2011 \text { dengan } \\
\text { menggunakan jam kerja } 8 \text { jam/hari, ternyata perusahaan } \\
\text { mengalami kekurangan kapasitas waktu produksi sebesar - } \\
\text { 265,62 jam, untuk mengatasi hal tersebut maka diberikan } \\
\text { usulan penambahan jam kerja menjadi } 9 \text { jam/hari, sehingga } \\
\text { kekurangan waktu dapat diatasi. }\end{array}$ \\
\hline 5 & $\begin{array}{l}\text { Fatmawati } \\
(2011) \text { JTM } \\
\text { Vol. 01 N0.02 } \\
\text { Tahun 2013, } \\
351-354\end{array}$ & $\begin{array}{lr}\text { Analisis } & \text { Kapasitas } \\
\text { Produksi } & \text { Dengan Metode } \\
\text { Capacity } & \text { Requirement } \\
\text { Planning (CRP) Di PT. } \\
\text { Hanil Jaya Stell }\end{array}$ & $\begin{array}{l}\text { Permintaan, } \\
\text { Kapasitas }\end{array}$ & $\begin{array}{l}\text { Hasil yang didapat adalah kapasitas yang tersedia selama } \\
\text { tahun } 2011 \text { maksimum } 546 \text { jam dan minimum } 564 \text { jam, } \\
\text { sedangkan kapasitas yang diperlukan pada reheating furnace : } \\
\text { minimum } 42,108 \text { jam maksimum } 47,094 \text { jam. Roughing mill } \\
\text { minimum } 421,08 \text { jam dan maksimum } 470,94 \text { jam. Colling } \\
\text { bed minimum } 561,44 \text { jam dan maksimum } 27,92 \text { jam. } \\
\text { Handling minimum dan maksimum } 1098,86 \text { jam. Bending } \\
\text { minimum } 982,52 \text { jam dan tenaga kerja di stasiun kerja } \\
\text { handling } 2 \text { orang. }\end{array}$ \\
\hline
\end{tabular}

dalam perumusan teori penelitian ini adalah sebagai Tabel 1. Berikiut ini : 


\section{KERANGKA PEMIKIRAN}

Untuk dapat melakukan proses penelitian dengan menggunakan metode Capacity Requirement Planning dengan langkah-langkah sebagai berikut :

a. Menentukan kapasitas work center: identifikasi dan menentukan work center, menghitung kapasitas work center, sebagai set dari sebuah atau beberapa mesin dan operator yang dapat dipertimbangkan sebagai sebuah unit untuk tujuan perencanaan kapasitas dan penjadwalan dengan menggunakan versi kapasitas Calculated yaitu didasarkan pada waktu kerja tersedia dikalikan utilitas dan efisiensi dari mesin dan versi Available work time yaitu waktu yang dijadwalkan untuk produksi bernilai kurang dari waktu maksimum yang tersedia. Dengan rumus $:$ calculated capacity $=$ available work time $\mathrm{x}$ utilization $\mathrm{x}$ efficiency Dalam lingkungan job shop, available work time adalah : available work time per period $=$ number of workers or machines $\mathrm{x}$ hour/shifts/work day $\mathrm{x}$ work days/period. Menghitung utilisasi dan efisiensi adalah Utilisasi $=$ jumlah jam dipakai kerja/jumlah jam kerja tersedia. Efisiensi $=$ jumlah jam standar kerja/jumlah aktual jam kerja.

b. Memperoleh informasi pesanan dan routing: informasi scheduled receipts dan planned order releases, informasi routing untuk setiap item pesanan.

Menghitung beban (load) untuk setiap work center untuk setiap periode perencanaan, dengan menggunakan backward scheduling, dan menggunakan infinite loading. Kemudian kalikan beban untuk setiap item dengan jumlah item yang dijadwalkan dalam suatu periode waktu.

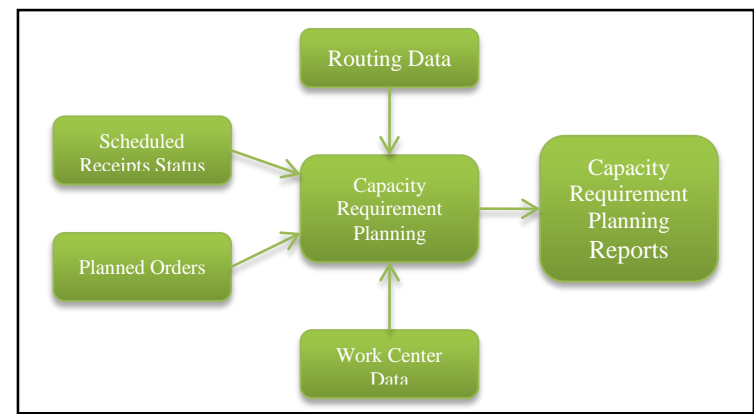

Gambar 2.2 Alur Proses Kerangka Pemikiran Capacity Requirement Planning

\section{METODE PENELITIAN}

Penelitian yang akan dilakukan menggunakan jenis penelitian deskriptif kuantitatif adalah penelitian yang dilakukan untuk mengetahui nilai variabel mandiri baik satu variabel atau lebih (independen) tanpa membuat perbandingan atau menghubungkan dengan variabel lain. Penelitian ini dapat memperoleh data dengan bentuk angka atau data kualitatif yang diangkakan Data yang diperoleh dari penelitian kuantitatif deskriptif ini meliputi:

a. Data primer, yang meliputi data dari siklus produksi yang termasuk jenis mesin, waktu yang digunakan dalam siklus produksi, jumlah mesin, kapasitas mesin.

b. Data sekunder, yang meliputi data yang akan diperoleh melalui observasi sumber daya yang digunakan dengan proses wawancara dengan pihak pengelola TFME.

\section{LOKASI DAN OBYEK PENELITIAN}

Obyek yang akan digunakan untuk penelitian ini adalah Ruang Produksi Teaching Factory Manufacture Electronics Politeknik Negeri Batam dengan lingkup penelitian yaitu bagian produksi G-Robo (General Robotic Platform) yaitu PCB sebagai basic penempatan komponen dari G-Robo.

\section{HASIL DAN PEMBAHASAN}

Penelitian ini difokuskan untuk proses produksi G-Robo dengan menggunakan PCB (Printed Circuit Board) sebagai landasan dasar komponen-komponen untuk pembentukan produk G-Robo. Untuk itu perencanaan 
Rika Kartika S \& Aditya Wirangga, Perencanaan Kapasiatas Produksi Dengan...

kapasitas akan memberikan kontribusi dalam menentukan tingkat kapasitas yang dibutuhkan dalam melakukan penjadwalan produksi yang bermanfaat bagi pencapaian target produksi. Tujuan dari penelitian ini adalah merencanakan kapasitas produksi dengan menggunakan metode Capacity Requirement Planning di TFME Politeknik Negeri Batam agar lebih bermanfaat bagi pencapaian target produksi bukan hanya untuk produksi G-Robo nantinya tetapi untuk produksi produk yang lainnya.

Analisis data dilakukan dengan perhitungan perencanaan kebutuhan kapasitas produksi dengan metode Capacity Requirement Planning yang akan menghasilkan data perhitungan kapasitas produksi yang dibutuhkan dalam periode yang telah ditentukan sebelumnya. Metode pengukuran waktu yang digunakan adalah metode jam henti. Pengamatan dilakukan secara random untuk setiap bagian kegiatan pembuatan PCB pada setiap work centre dimana masing - masing work centre menghasilkan 1 unit setara dengan 8 pcs produk PCB Double Layer G-Robo. Penentuan allowance time berdasarkan jam kerja waktu normal di TFME Politeknik Negeri Batam yaitu 1 jam setara dengan 60 menit sedangkan waktu normal TFME adalah 8 jam/hari kerja setara dengan 480 menit/hari dan waktu baku TFME adalah 7 jam/hari kerja setara dengan 420 menit/hari. Hasil perhitungan kebutuhan kapasitas dapat dilihat dari tabel berikut ini

Tabel 4.1. Planned Orders and Load

\begin{tabular}{ccc}
\hline \multicolumn{3}{c}{ Periode } \\
\hline Bulan & QTY & Satuan \\
Feb-15 & 6 & Pcs \\
Mar-15 & 6 & Pcs \\
Jun-15 & 100 & Pcs \\
Sep-15 & 7 & Pcs \\
Okt-15 & 55 & Pcs \\
Jan-16 & 10 & Pcs \\
Mar-16 & 150 & Pcs \\
\hline
\end{tabular}

Sumber : TFME Politeknik Negeri Batam
Tabel 4.2. Planned Order Releases

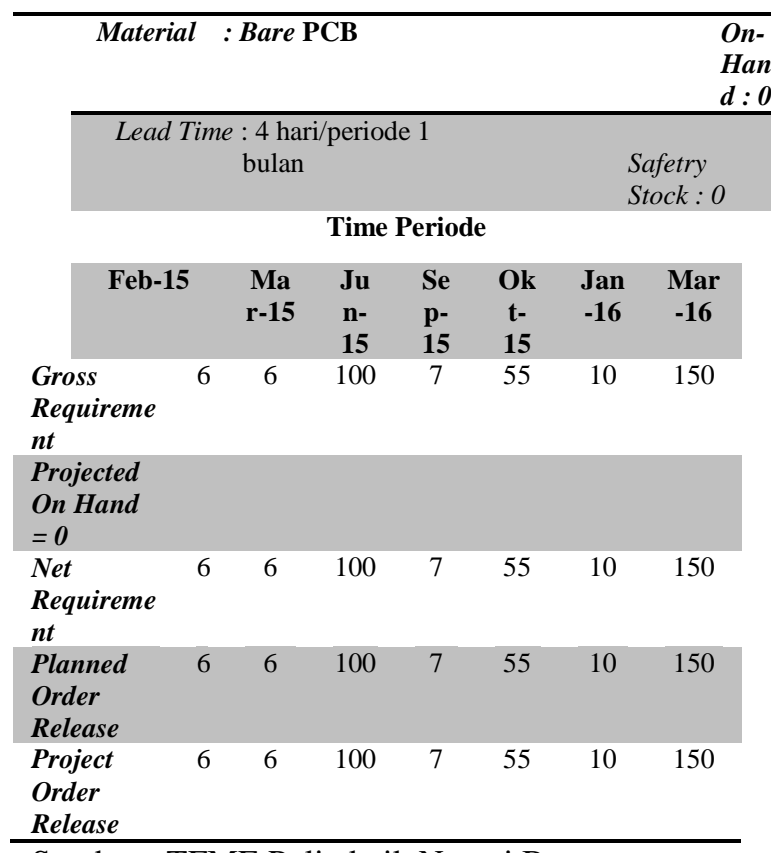

Sumber : TFME Politeknik Negeri Batam

Berdasarkan tabel 4.3 diatas, maka dapat diketahui kebutuhan kotor yang didapat dari JIP (contoh bulan Maret 2016). Rencana produksi (Maret - Project On Hand $)=150-0=$ 150 Pcs. Persediaan ditangan adalah yang dimiliki perusahaan $=0$ Pcs . Kebutuhan bersih didapat dari : Kebutuhan kotor - Persediaan ditangan $=150-0=150$ pcs. Rencana penerimaan komponen $=0$ Pcs, karena $\mathrm{PCB}$ dibuat oleh perusahaan jadi tidak ada pemesanan PCB. Proyeksi persediaan didapat dari $=$ Kebutuhan bersi - rencana penerimaan $=$ $150-0=150$ Pcs. Rencana pelepasan sama dengan 150 Pcs, karena lead time $=4$ hari yang masih dalam 1 periode (bulan). Jumlah hari kerja dan kerja TFME Politeknik Negeri Batam dalam satu minggu terdiri dari 4 hari kerja dan 1 shift dengan jumlah jam kerja per hari adalah 8 jam. Jumlah waktu kerja tersedia berdasarkan perhitungan libur yang telah ditetapkan oleh perusahaan dapat dilihat pada tabel berikut ini. Kapasitas tersedia dihitung berdasarkan jam kerja efektif setiap hari dikalikan dengan jumlah hari kerja setiap bulan. 
Journal of Business Administration Vol 1, No.1, Maret 2017, hlm.1-9

Tabel 4.3. Schedule Receipts

\begin{tabular}{llll}
\hline Periode & $\begin{array}{l}\text { Jumlah } \\
\text { Hari } \\
\text { Kerja(Hari) }\end{array}$ & $\begin{array}{l}\text { Kapasitas } \\
\text { Tersedia } \\
\text { (jam) }\end{array}$ & $\begin{array}{l}\text { Operation } \\
\text { Time } \\
\text { (Hari) }\end{array}$ \\
\hline $\begin{array}{l}\text { Februari 2015 } \\
\text { Maret 2015 }\end{array}$ & 16 & 128 & 8 \\
Juni 2015 & 18 & 144 & 8 \\
September & 18 & 144 & 8 \\
2015 & & 144 & 8 \\
Oktober 2015 & 17 & & \\
Januari 2016 & 17 & 136 & 8 \\
Maret 2016 & 18 & 136 & 8 \\
\hline
\end{tabular}

Sumber : TFME Politeknik Negeri Batam

Data kapasitas terpasang untuk setiap mesin -mesin (Work Centre) pada proses satu siklus pembuatan PCB dapat dilihat dari proses Chart dan tabel untuk setup time dan run time dengan asumsi bahwa data design terlebih dahulu dikerjakan sebelum melakukan proses produksi PCB, untuk itu waktu kerja (run time) yang digunakan tidak dapat bersamaan dilakukan hanya saja pada saat melakukan pengeditan design maka waktu kerja yang digunakan dapat berbarengan dengan proses produksi, maka dapat dilihat seperti data berikut ini. Persiapan waktu (Setup Time) dan Waktu Kerja (Run Time) yang telah dihitung maka dapat diperkirakan dalam sehari kapasitas produksi yang terpasang sebanyak 1 PCB ukuran A4 dengan design khusus lingkup pembuatan PCB (Printed Circuit Board) GRobo dapat diproduksi sebanyak 8 Pcs dengan perkiraan waktu operasi sebanyak 5,12 jam.

Tabel 4.4. Work centres data

\begin{tabular}{|c|c|c|c|c|c|}
\hline \multirow{2}{*}{$\begin{array}{l}\text { No. } \\
\text { WC }\end{array}$} & Kegiatan & Bagian & Work Center & Setup Time & Run Time \\
\hline & & & (WC) & (Second) & (Second) \\
\hline 1 & Pemotongan PCB & & Jigsaw/gerinda & 300 & 3600 \\
\hline 2 & Pengeboran PCB & & CCD RouterPro & 900 & 2400 \\
\hline 3 & Brushing РСВ & & RMB 300 & 900 & 300 \\
\hline \multirow[t]{7}{*}{4} & $\begin{array}{l}\text { PTH (Plating } \\
\text { Through Hole) }\end{array}$ & $\begin{array}{c}\text { Cleaner } \\
\text { Black Hole }\end{array}$ & $\begin{array}{l}\text { Compacta L 30MD } \\
\text { Bak ke-4 }\end{array}$ & 1800 & 480 \\
\hline & & Rinsing & $\begin{array}{l}\text { Compacta L 30MD } \\
\text { Bak Pencuci }\end{array}$ & & 300 \\
\hline & & $\begin{array}{c}\text { Catalist } \\
\text { Black Hole }\end{array}$ & $\begin{array}{l}\text { Compacta L 30MD } \\
\text { Bak ke-5 }\end{array}$ & & 480 \\
\hline & & & ULM 400 & & \\
\hline & & & $\begin{array}{l}\text { Compacta L 30MD } \\
\text { Bak ke-6 }\end{array}$ & & \\
\hline & & Rinsing & $\begin{array}{l}\text { Compacta L 30MD } \\
\text { Bak Pencuci }\end{array}$ & & 300 \\
\hline & & Micro Etch & $\begin{array}{l}\text { Compacta L } 30 \\
\text { Omnibond Bak ke-4 }\end{array}$ & & 300 \\
\hline
\end{tabular}

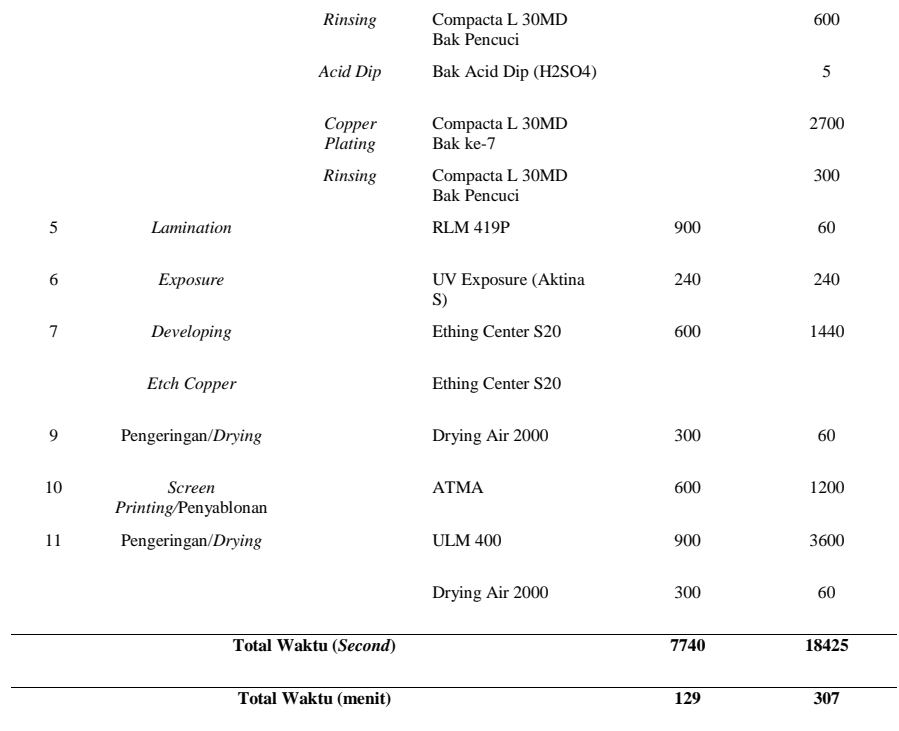

Faktor efisiensi dan utilisasi diperoleh melalui observasi di TFME Politeknik Negeri Batam seperti tabel berikut.

Dengan tingkat utilisasi sebesar $88 \%=0,88$ dan tingkat efisiensi sebesar $90 \%=0,90$ berdasarkan hitungan jam kerja yang digunakan, waktu tersebut merupakan kondisi performance aktual dari work centres.

Selanjutnya setelah diketahui berapa operation time per hari, maka dicari waktu produksi yang dibutuhkan untuk memenuhi permintaan produksi yang telah diterbitkan pada MRP khususnya permintaan produksi PCB untuk pembuatan G-Robo. Berikut adalah tabel waktu produksi yang dibutuhkan untuk memproduksi PCB selama beberapa bulan Maret dalam periode tahun 2016, dengan tingkat penyesuaian produksi terhadap produk reject atau disebut rejection tag adalah $10 \%=0,1$ berdasarkan metode six sigma DMAIC dalam penetuan capacity produksi. (abdul : 2014)

Berdasarkan kapasitas permintaan sebanyak 150 menjadi 165 kapasitas yang akan diproduksi dengan mempertimbangkan beberapa hal, baik untuk riset maupun reject sebelum diproduksi secara massal. 
Rika Kartika S \& Aditya Wirangga, Perencanaan Kapasiatas Produksi Dengan...

Tabel 4.6. Hasil Capacity Requirement Planning

\begin{tabular}{|c|c|c|c|c|c|}
\hline \multirow[t]{2}{*}{ Bulan } & \multicolumn{5}{|c|}{ Rencana Penggunaan Kapasitas Produksi } \\
\hline & $\begin{array}{l}\text { Demand } \\
\text { (Pcs) }\end{array}$ & $\begin{array}{l}\text { Kapasitas Produksi } \\
\text { Terpasang } \\
\text { (Pcs/Hari) }\end{array}$ & $\begin{array}{l}\text { Waktu Operasi } \\
\text { (hari) }\end{array}$ & $\begin{array}{l}\text { Kebutuhan } \\
\text { Kapasitas Aktual } \\
\text { (menit) }\end{array}$ & $\begin{array}{c}\text { Kebutuhan } \\
\text { Kapasitas } \\
\text { Aktual } \\
\text { (jam) }\end{array}$ \\
\hline Februari'16 & 165 & 8 & 14 & 6720 & 112 \\
\hline
\end{tabular}

Sumber : Pengolahan Data

Keterangan data adalah :

- Kapasitas perhari terpasang = kapasitas output per shift (8 pcs) x Jumlah shift kerja $(1$ shift $)=8 \times 1=8$ pcs $/$ hari $=1$ unit PCB A4

Waktu operasi adalah waktu yang digunakan untuk menyelesaikan permintaan berdasarkan kemampuan kapasitas maksimal. Sehingga perumusannya adalah permintaan (demand) dibagi dengan kapasitas produksi terpasang $=165$ pcs $: 8$ $\mathrm{pcs} /$ hari $=21$ unit dimana 1 unit $\mathrm{PCB}$ A4 dikerjakan dalam waktu 5,12 jam sehingga untuk menyelesaikan 21 unit menghabiskan waktu selama 112 jam
= 14 hari, untuk itu berdasarkan kebutuhan penyesuaian kapasitas dalam produksi maka jumlah hari yang dibutuhkan untuk Operation Time (waktu operasi) adalah selama 14 hari.

- Kebutuhan waktu aktual adalah konversi dari waktu operasi kedalam satuan menit yaitu $=14$ hari $\times 8$ jam/shift $\times 60$ menit $=6720$ menit $=$ 112 jam.

Perencanaan Capacity Requirement Planning Berdasarkan kapasitas penerimaan dan matrik setup time dapat ditentukan capacity requirement planning untuk tiap work centre pada saat produksi PCB untuk G-Robo pada bulan Maret 2016 seperti pada tabel 4.7

Tabel 4.7. Laporan Perhitungan Capacity Requirement Planning

\begin{tabular}{|c|c|c|c|c|c|c|c|}
\hline $\begin{array}{l}\text { No. } \\
\text { WC }\end{array}$ & Work Center & $\begin{array}{c}\text { Waktu } \\
\text { yang } \\
\text { tersedia }\end{array}$ & $\begin{array}{l}\text { Tingkat } \\
\text { Utilisasi }\end{array}$ & $\begin{array}{l}\text { Tingkat } \\
\text { Efisiensi }\end{array}$ & $\begin{array}{c}\text { Kapasitas } \\
\text { Tersedia }\end{array}$ & $\begin{array}{c}\text { Kebutuhan } \\
\text { Aktual }\end{array}$ & $\begin{array}{c}\text { Kelebihan/ } \\
\text { kekurangan } \\
\text { kapasitas }\end{array}$ \\
\hline & $(\mathbf{W C})$ & 1 & 2 & 3 & $(1 \times 2 \times 3)$ & 5 & $(4-5)$ \\
\hline 1 & Jigsaw/gerinda & 8640 & 0.88 & 0.9 & 6804 & 6720 & 84 \\
\hline 2 & CCD RouterPro & 8640 & 0.88 & 0.9 & 6804 & 6720 & 84 \\
\hline 3 & RMB 300 & 8640 & 0.88 & 0.9 & 6804 & 6720 & 84 \\
\hline \multirow[t]{9}{*}{4} & Compacta L 30MD Bak ke-4 & 8640 & 0.88 & 0.9 & 6804 & 6720 & 84 \\
\hline & $\begin{array}{l}\text { Compacta L 30MD Bak } \\
\text { Pencuci }\end{array}$ & 8640 & 0.88 & 0.9 & 6804 & 6720 & 84 \\
\hline & Compacta L 30MD Bak ke-5 & 8640 & 0.88 & 0.9 & 6804 & 6720 & 84 \\
\hline & ULM 400 & 8640 & 0.88 & 0.9 & 6804 & 6720 & 84 \\
\hline & Compacta L 30MD Bak ke-6 & 8640 & 0.88 & 0.9 & 6804 & 6720 & 84 \\
\hline & $\begin{array}{l}\text { Compacta L 30MD Bak } \\
\text { Pencuci }\end{array}$ & 8640 & 0.88 & 0.9 & 6804 & 6720 & 84 \\
\hline & $\begin{array}{l}\text { Compacta L } 30 \text { Omnibond } \\
\text { Bak ke-4 }\end{array}$ & 8640 & 0.88 & 0.9 & 6804 & 6720 & 84 \\
\hline & $\begin{array}{l}\text { Compacta L 30MD Bak } \\
\text { Pencuci }\end{array}$ & 8640 & 0.88 & 0.9 & 6804 & 6720 & 84 \\
\hline & Bak Acid Dip (H2SO4) & 8640 & 0.88 & 0.9 & 6804 & 6720 & 84 \\
\hline
\end{tabular}


Journal of Business Administration Vol 1, No.1, Maret 2017, hlm.1-9

\begin{tabular}{clllllll}
\hline & Compacta L 30MD Bak ke-7 & 8640 & 0.88 & 0.9 & 6804 & 6720 & 84 \\
& $\begin{array}{l}\text { Compacta L 30MD Bak } \\
\text { Pencuci }\end{array}$ & 8640 & 0.88 & 0.9 & 6804 & 6720 & 84 \\
$\mathbf{5}$ & RLM 419P & 8640 & 0.88 & 0.9 & 6804 & 6720 & 84 \\
$\mathbf{6}$ & UV Exposure (Aktina S) & 8640 & 0.88 & 0.9 & 6804 & 6720 & 84 \\
$\mathbf{7}$ & Ething Center S20 & 8640 & 0.88 & 0.9 & 6804 & 6720 & 84 \\
& Ething Center S20 & 8640 & 0.88 & 0.9 & 6804 & 6720 & 84 \\
$\mathbf{9}$ & Drying Air 2000 & 8640 & 0.88 & 0.9 & 6804 & 6720 & 84 \\
$\mathbf{1 0}$ & ATMA & 8640 & 0.88 & 0.9 & 6804 & 6720 & 84 \\
$\mathbf{1 1}$ & ULM 400 & 8640 & 0.88 & 0.9 & 6804 & 6720 & 84 \\
& Drying Air 2000 & 8640 & 0.88 & 0.9 & 6804 & 6720 & 84 \\
\hline
\end{tabular}

Keterangan dari Tabel 4.7 perencanaan pembuatan laporan capacity requirement planning waktu yang tersedia dihitung berdasarkan :

14 hari/bulan x 8 jam/hari x 60 menit/jam $=6720$ menit per bulan dengan tingkat efisiensi dan utilisasi merupakan kondisi actual perfomance dari setiap work centres.

Kapasitas yang tersedia dalam periode ini adalah 6804 menit selama 18 hari kerja untuk menyelesaikan pesanan PCB G-Robo sebanyak 165 pcs, dan waktu aktual yang dibutuhkan untuk menyelesaikan pesanan tersebut hanya 6720 menit selama 14 hari kerja sehingga dengan menggunakan metode CRP ini dapat menyimpan operation cost selama 4 hari 84 menit sehingga TFME Politeknik Negeri Batam dapat meminimalisir biaya yang diakibatkan dari proses produksi (save cost) serta pesanan untuk PCB G-Robo juga dapat diselesaikan tepat pada waktunya dengan cepat dan berkualitas.

\section{KESIMPULAN DAN SARAN}

Penerapkan metode Capacity Requirement Planning (CRP) di Teaching Factory Manufacture Elecronics Politeknik Negeri Batam dapat memenuhi permintaan konsumen tanpa melakukan Over Time ataupun subkontrak dengan perusahaan sejenis lainnya yang dapat mengakibatkan biaya operasi produksi lebih tinggi. Sehingga hasil yang didapat untuk memproduksi 165 pcs PCB double layer dengan metode CRP membutuhkan waktu selama 14 hari kerja dengan deskripsi waktu 1 unit PCB setara 8 pcs PCB dapat diselesaikan dalam waktu 5,12 jam/hari dan hanya membutuhkan 21 unit PCB ukuran A4. Berdasarkan hasil olahan data dalam pembahasan maka dapat diambil kesimpulan bahwa dalam merencanakan kapasitas produksi harus mempertimbangkan sumber daya yang ada didalam perusahaan tersebut dan melakukan penyesuaian dalam proses produksi dengan tingkat defect yang akan terjadi sehingga dapat diminimalisir produk yang reject. Dalam penelitian ini penulis membatasi penelitian megenai produksi PCB hanya untuk permintaan PCB G-Robo yang akan digunakan untuk produksi G-Robo nantinya.

Saran yang dapat diberikan selama penelitian untuk perusahaan sebagai berikut ini Pihak perusahaan hendakhnya menambah man power agar lebih tersturuktur dan efisien dlam pelaksanaan produksi di TFME. Penerapan metode CRP agar dapat memberikan hasil yang optimal sehingga hendaknya dalam penelitian selanjutnya perusahaan perlu mendukung dan mempersiapkan sarana sarana pendukung lainnya seperti data yang akurat, manajemen yang baik, pengetahuan yang cukup dari pemakai metode CRP ataupun metode penelitian yang lainnya.

\section{DAFTAR PUSTAKA}

Arnold, J.R. Tony \& Stephen, N. (2008). Introduction to Material Management (Sixth Edition). Uppe Saddle River, New Jersey : Pearson Practice Hall.

Achbar, Yovial. (2010). Perencanaan Kapasitas Produksi Outer Trafo Dengan Metode Capacity Requirement Planning (CRP) Di PT. Bambang Djaja Surabaya. 
Rika Kartika S \& Aditya Wirangga, Perencanaan Kapasiatas Produksi Dengan...

Diperoleh dari Library Website : eprints.upnjatim.ac.id/1706

Fatmawati., \& Umar, wiwi. (2013). Analisis Kapasitas Produksi Dengan Metode Capacity Requirement Planning (CRP) Di PT. Hanil Jaya Stell. JTM, 01 (02), $351-354$.

Gaspersz, Vincent. (2004). Production Planning and Inventory Control Berdasarkan Pendekatan Sistem Terintegrasi MRP II dan JIT Menuju Manufacturing 21, PT. Gramedia Pustaka Utama.

Kumar, S.Anil \& N. Suresh. (2008). Production And Operation Management (Second Edition), New Age International (P) LTD. ISBN : 978-81224-2425-6. New Delhi.

Machi, Ikedanaka., \& Omiya, Suginami-ku. (2014). Stability-Based Short-Term Capacity Requirement Planning Under Uncertainty. Retrived From Journal Int. j. Of Automation Technology .,17 (8). Procedia CIRP 19 (123 - 128). Library Website: sciencedirect.com

Nainggolan, C.A. (2015). Perencanaan Kapasitas Produksi Dengan Capacity
Requirement Planning Di PT. Sinar Utama Nusantara. Diperoleh dari Library Website repository.usu.ac.id/xmlui/handle/12345 153454

Purnama, Jaka., \& Suhartini. (2014). Metode Material Requirement Planning Untuk Mengoptimalkan Output Produksi. ISBN: 978-979-3649-81-8. Institut Teknologi Adhi Tama. Surabaya.

Purnamawati, Erlina. (2009). Perencanaan Kapasitas Waktu Produksi yang Optimal Dengan Menggunakan Metode Capacity Requirement Planning Di PT. SPI Surabaya. Diperoleh dari Library Website

Ejournal.upnjatim.ac.id/index.php/tekma pro/article/view/297

Putranto, Ramadhan Fakhri ., \& et all. (2012) Perencanaan dan Pengendalian Produksi. Retrieved from Institut Teknologi Bandung, Library website: http://www.academia.edu/5471879/Mod ul_7_Kelompok_20_-_Laporan.

Sugiyono. (2008). Metode Penelitian Administrasi. Bandung: Alfabeta 